\title{
Activity Identifier
}

National Cancer Institute

\section{Source}

National Cancer Institute. Activity Identifier. NCI Thesaurus. Code C93704.

A unique symbol that establishes identity of an activity. 